\title{
A Sensitive Procedure for the Rapid Determination of Mandelic Acid by Flow Injection Analysis and Chemiluminescence Detection
}

\author{
Seikh Mafiz Alam, Chi Wan Jeon, Mohammad Mainul Karim, Sang Hak Lee," \\ Saikh Mohammad Wabaidur, Yeoun Suk Suh, and Hỵe Young Chung
}

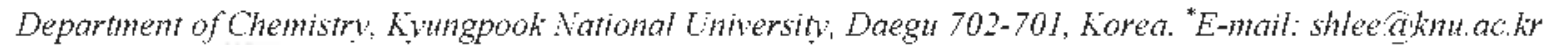 \\ Korea Institute of Geoscience \& Mineral Resources, Daejeon 305-350, Korea \\ Received March 6, 2008, Accepted Nowember 14, 2008
}

\begin{abstract}
A rapid and sensitive chemiluminescence (CL) method using flow-injection (FI) has been developed for the detemination of mandelic acid which is based on the enhancement of mandelic acid to the CL intensity of Ru(biPy) ${ }_{3}{ }^{2-}$-Ce(IV) systen. Ihe enhancenent effect was dependent on the concentration of mandelic acid, based on which, CL system was established for the detenmination of mandelic acid. The concentrations of Ru(bipy ) ${ }^{2-}$, $\mathrm{Ce}(\mathrm{IV})$, and $\mathrm{H}_{2} \mathrm{SO}_{4}$ were optimized. Under the optimum experimental conditions, the linear range and detection limit are $1.46-342.0 \mathrm{tg} / \mathrm{mL}$ and $0.072 \mathrm{tg} / \mathrm{mL}$, respectively. The correlation coefficient (R) was 0.99732 . The utility of this method was demonstrated by determining mandelic acid in capsules and human urine sample.
\end{abstract}

Key Words: Chemiluminescence. Flow-injection analysis (FIA). Mandelic acid

\section{Introduction}

Mandelic Acid (MA), phenylglycollic acid is an alphahydroxy acid (AHA) (Figure 1) which has a hydrosyl group on the carbon atom next to the acid group. In human. MA is a major metabolite of styrene and used as biological indicator of occupational exposure to styrene. 'In plastic industries, styrene is widely used and has been implicated as reproductive toxicant, neurotoxicant and possible carcinogen. In human and rodents. styrene can be metabolized to sty'rene epoxide (SO) by the microsomal cytochrome $\mathrm{P}-450$ dependent liver monooxygenase and further metabolized to 1,2-phenylethanediol by epoxide hydrolase then 1.2-phenylethanediol can be metabolized to MA that is excreted in urine. ${ }^{2}$ Recent studies indicated that styrene epoxides accounted for the sty rene toxicity and contribute to the genotoxicity of styrene in human blood ly'mphocytes. ${ }^{3}$ Both sty'rene epoxide and 1.2-phenylethanediol are chirals and show stereo-selectivity in metabolism in vivo leading to different urinary excretions of MA enantiomers. ${ }^{+} \mathrm{MA}$ and its derivatives are a type of chiral synthons which are useful for the production of different pharmaceuticals. such as cephalosporins. antiobesity agents. semisynthetic penicillins and antitumor agents. ${ }^{\text {s. }}$

The few reported methods for the determination of MA are HPLC ' gas-chromatography. ${ }^{8.9}$ capillary electrophoresis. ${ }^{16}$ electrochemiluminescence ${ }^{11}$ and spectrophotometry. ${ }^{12}$ Chemiluminescence (CL) methods provide many advantages for pharmaceutical determinations such as high sensitivity, high selectivity and small amount of chemical consumption. cost effectiveness. simple sample preparation and instrumentation. ${ }^{13.15}$

Tris (2.2'-bipyridyl) ruthenium(II) has been used as the basis of CL detection of a wide range of compounds after oxidation to the nithenium(III) complex. ${ }^{16}$ The analyte interacts with the ruthenium(III) complex reducing it to the ruthenum(II) complex in an excited state. which then emits $\mathrm{CL}$ as it returns to the ground state. In the present study. a flow in- jection procedure for MA determination with CL detection was proposed in which ruthenium(II) was oxidized by $\mathrm{Ce}$ (IV) solution. The CL emission intensity depended on the concentration of the analyte in the CL system.

This work describes a relatively sensitive. rapid and reproducible CL method for MA determination based on tris (2.2'-bipyridyl)ruthenium(II) without sample pretreatment process. To the best of our knowledge. no method has so far been reported for the determination of MA using flow-injection CL technique. The proposed method was successfully' applied to the determination of MA in commercial pharmaceutical formulation. The results of recovery of MA in urine sample were satisfactory. The reaction mechanism was also proposed.

\section{Experimental}

Reagents. All chemicals were of analytical reagent grade and were used without further purification. All solutions were prepared with distilled deionised water. Mandelic acid was purchased from Sigma (St. Louis, USA). The stock solution of MA was $\left(1 \times 10^{-2} \mathrm{M}\right)$ prepared by dissolving $1.52 \mathrm{gm}$ of MA in water and diluting to $1000 \mathrm{~mL}$ with water. Solutions of the desired concentrations were obtained by diluting the stock solution to a volume with water. The solution of Ru(bipy) $z^{2-}$ $\left(10^{-2} \mathrm{M}\right)$ was obtained by dissolving $0.37+3 \mathrm{gm}$ of tris $\left(2.2^{\prime}\right.$ -<smiles>O=C(O)C(O)c1ccccc1</smiles>

Figure 1. The structure of mandelic acid. 
bipy ridal) rutherium (II) (Fluka. Gillingham. Dorset. UK) in water and diluting to $500 \mathrm{~mL}$. $1 \mathrm{M} \mathrm{Ce}\left(\mathrm{SO}_{4}\right)_{2}$ was made in $1 \mathrm{M}$ $\mathrm{H}_{2} \mathrm{SO}_{4}$

Apparatus. FIA (Flow-injection analysis) used in our work is shown in Figure 2. Two peristaltic pumps (Ismatec Model 404) were used to convey all solutions. Pump $P_{1}$ delivered carrier stream $\left(\mathrm{H}_{3} \mathrm{O}\right)$ at a flow rate of $2.0 \mathrm{~mL} \mathrm{~min}^{-1}$ which was incorporated with sample solution in a Rheodyne (Cotati. CA. USA) Model 7125 six-way injection valve with a loop while pump $P_{2}$ was used to convey all other CL reagents at an equal flow rate of $2.0 \mathrm{~mL} \mathrm{~min}{ }^{-1}$ for each line. PTFE tubing $(0.8 \mathrm{~mm}$ 1.d) was used throughout the manufold to carry all components. A Spex (Edison. NJ, USA) Model FL11l spectrofluorimeter equipped with a coiled glass flow cell $(1.0 \mathrm{~mm}$ i.d. $20 \mathrm{~mm}$ total diameter) was used for detecting and recording the CL intensity of the reaction product. The Spex DM 3000 program was ussed for data acquisition and data analysis. For the CL measurement, the light source of the spectrofluorimeter was switched off. The slit width of the emission monochromator was $0.25 \mathrm{~mm}$. The high voltage for the photomultiplier tube (R 928. Hamamatsu. USA) was set to $950 \mathrm{~V}$.

Pocedure. The FIA configuration consisted of a threechanuel manfold using two pumps. The schematic diagram of the manifold is shown in Figure 2. Prior to the CL measurement acquisition corresponding to the solution containing ruthenum (II) solution stream was mixed with acidic Ce(IV) solution stream in a three-way " $\mathrm{T}_{1}$ " connector. The resulting stream was merged with the carner solution in the second " $\mathrm{T}_{2}$ " connector and then reached the flow cell in the fluorimeter. accompany ing the remarkable mcrease of CL intensity. The full CL intensity versus time was recorded. The increase in the CL intensity produced when a solution containing the MA was incorporated into the carrier stream. in relation to the original CL signal corresponding to a blank. was proportional to the MA concentration and was used as analytical signal. This signal was measured as peak height.

Sample preparation. A total 20 tablets of Methenamine which contains mandelic acid, accurately weighed, then ground and mixed well. An appropnate amount of MA equivalent to one tablet (500 $\mathrm{mg}$ of Methenamine) was accurately

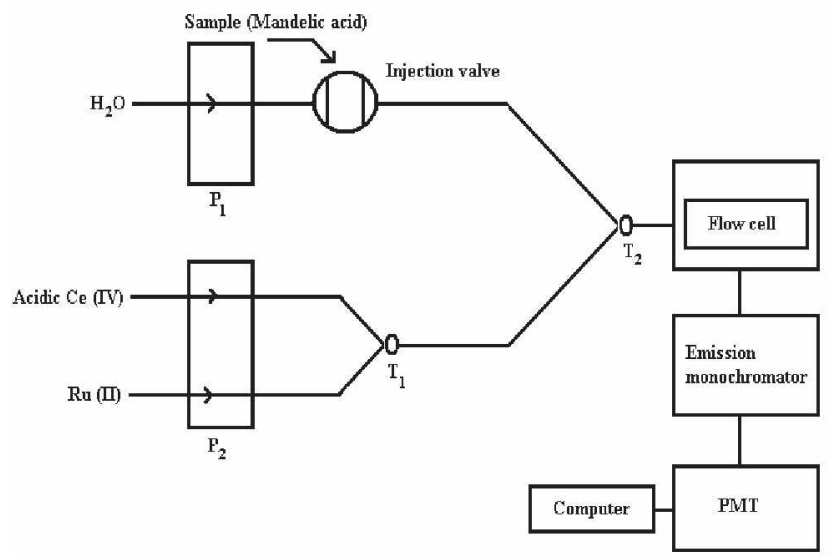

Figure 2. Schematic diagram of the FIA-CL manifold employed for the yuantitative detemination of mandelic acid. $\mathrm{P}_{1}, \mathrm{P}_{2}$. Peristaltic pumps: $T_{1}, T_{2}$ : $Y$-pieces. weighed and dissolved in water by sonication in a $250 \mathrm{~mL}$ volumetric flask and diluting with water to $250 \mathrm{~mL}$. The dissolved sample was filtered through Whatman No. 1 filter paper and diluted with water to volume to obtain the appropnate concentration for analysis. Immediately after collection. 25 $\mathrm{mL}$ aliquots of urine samples from 5 volunteers were spiked with $\mathrm{MA}$ at variable concentration levels, in order to calculate the recoveries of the proposed method. From these pools. 0.5 $\mathrm{mL}$ aliquots were distributed to $0.5 \mathrm{~mL}$ Eppendorf and stored at $-18^{\circ} \mathrm{C}$ until analysis.

\section{Results and Discussion}

Selection of the concentration of Ru(bipy) ${ }_{3}{ }^{2+}$. It is well known that for the CL system involved in Ru(bipy) ${ }^{2-}$. the light emission is generated front the excited state species [Ru(bipy ) $5^{2-}$ ] which is the reaction product of Ru(bipy) $3^{3-5}$ with the appropriate reductants. contnionly the analytes. so Ru(bipy $)_{3}{ }^{2+}$ is the luninophor of the system ${ }^{17}$ In order to find the optimum concentration of Ru(bipy) $s^{2-}$ used for the chentiluminogenic reagent for the determination of MA the effect of Ru(bipy) $)_{3}{ }^{2-}$ concentration on the $\mathrm{CL}$ intensity obtained from the Ru(bipy) ${ }_{3}{ }^{2+}-\mathrm{Ce}$ (IV)-MA systen was investagated. With the solutions containing a vanable amount of Ru(bipy) ${ }_{3}{ }^{2-}$ from $3.3 \times 10^{-5} \mathrm{M}$ to $3.3 \times 10^{-3} \mathrm{M} \mathrm{MA}$, and $2.3 \times 10^{-3} \mathrm{M} \mathrm{Ce}(\mathrm{IV})$ (in $3.3 \times 10^{-2} \mathrm{M} \mathrm{H}_{2} \mathrm{SO}_{4}$ ), the effect of the concentrations of Ru(bipy) $z^{2-}$ on the system was investigated by determining the CL intensity of Ru(bipy) ${ }_{2}{ }^{-}$- Ce(IV) system (blank) and $\mathrm{Ru}(\mathrm{bipy})_{3}{ }^{2+}-\mathrm{Ce}(\mathrm{IV})-\mathrm{MA}$. From the experimental results shown in Figure 3. the CL responses of MA are strongly dependent on Ru(bipy) s. ${ }^{2+}$. The CL intensity increased from $3.3 \times 10^{-5} \mathrm{M}$ to $6.7 \times 10^{-4} \mathrm{M}$ of Ru(bipy) ${ }^{2-}$ and then decreased. The $\mathrm{CL}$ intensity increased with increasing $\mathrm{Ru}$ (bipy) ${ }_{3}{ }^{2-}$ concentration which can be attributed to the rapid $\mathrm{CL}$ reaction because of the increased reagent to analyte ratio. ${ }^{1 \&}$ The decreased $\mathrm{CL}$ intensity beyond the colkentration of $6.7 \times 10^{-4} \mathrm{M}$ of $\mathrm{Ru}(\mathrm{bipy})_{3}{ }^{3-}$ may be due to the self-quenching phenomenon. Therefore $6.7 \times 10^{-4} \mathrm{M}$ of Ru(bipy) ${ }_{3}{ }^{3+}$ was chosen for further experiments.

Selection of the concentration of Ce (IV). In order to find

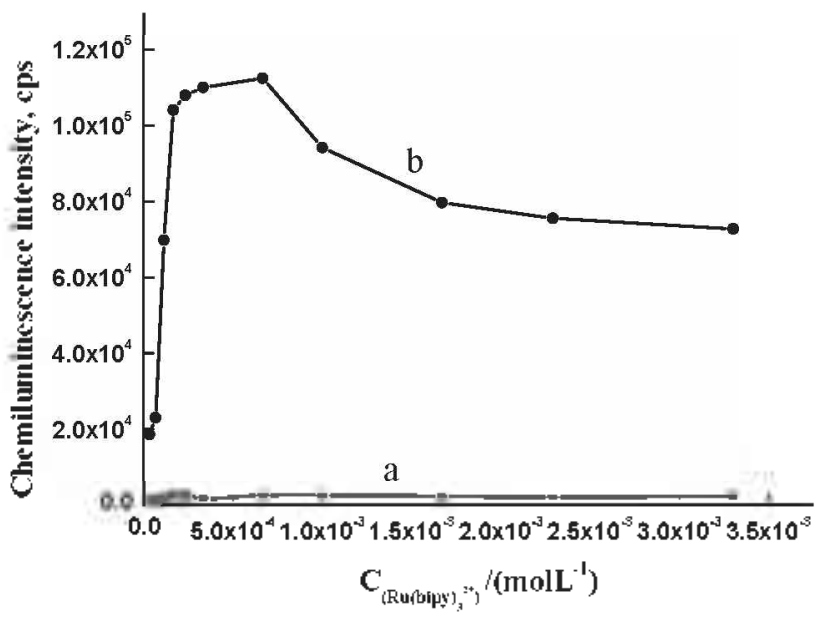

Figure 3. Effect of the concentration of Ru(bipy ) ${ }^{2-}$ on chemiluminescence intensity. Conditions: $3.3 \times 10^{-3} \mathrm{~mol} \mathrm{~L}^{-1}$ mandelic acid, $2.3 \times 10^{-3} \mathrm{~mol} \mathrm{~L}^{-1} \mathrm{Ce}(\mathrm{IV})$ and $3.3 \times 10^{-1} \mathrm{~mol} \mathrm{~L}^{-1} \mathrm{H}_{2} \mathrm{SO}_{4}$; (a) Ru(bipy) ${ }_{3}{ }^{2+}$. Ce(IV) system; (b) Ru(bipy ${ }_{3}{ }^{2-}$ mandelic acid-Ce(IV) system. 


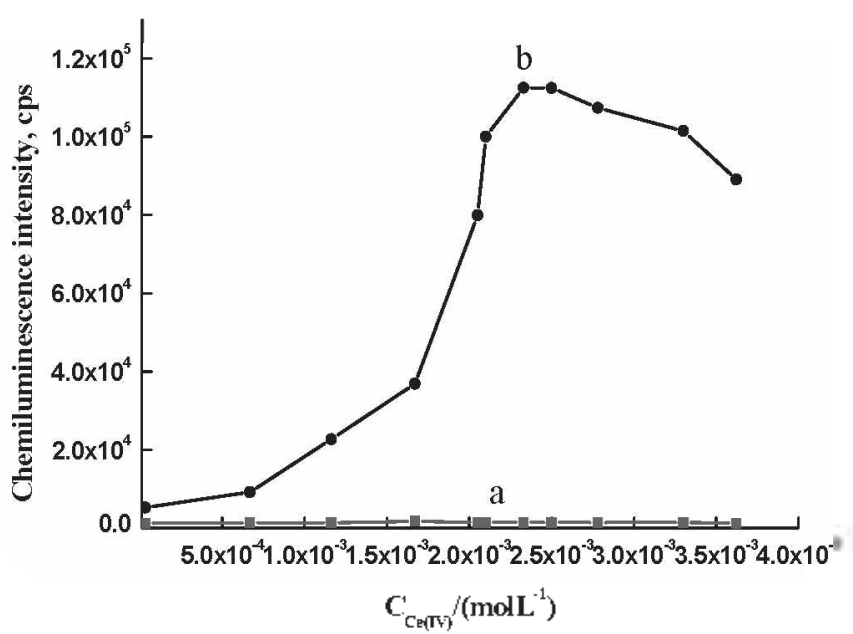

Figure 4. Effect of the concentration of Ce(IV) on chemiluminescence intensity. Conditions: $3.3 \times 10^{-3} \mathrm{~mol} \mathrm{~L}{ }^{-1}$ mandelic acid, $6.7 \times 10^{-1}$

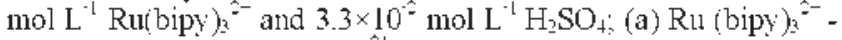
Ce(IV) svstem; (b) Ru(bipy) ${ }^{\hat{*}}{ }^{+}$-mandelic acid-Ce(IV) svstem.

the optimum concentration of Ce(IV) used for the chemiluminogenic reaction for the determination of MA. the effect of $\mathrm{Ce}$ (IV) concentration on the chemiluminescence intensity obtained from the Ru(bipy) $3^{{ }^{2}-}$-Ce(IV)-MA system was investigated. $\mathrm{Ce}\left(\mathrm{SO}_{4}\right)_{2}$ was utilized as the oxidant in this $\mathrm{CL}$ system. As the oxidant the concentration of $\mathrm{Ce}$ (IV) could affect the CL intensity of the systems and the corresponding experiments were carried out under the fixed amount of $6.7 \times 10^{-4}$ $\mathrm{M} \mathrm{Ru}(\text { bipy })_{3}{ }^{{ }^{2-}}$ and the variable concentration of $\mathrm{Ce}\left(\mathrm{SO}_{4}\right)_{2}$ in the range of $3.33 \times 10^{-5}-3.62 \times 10^{-3} \mathrm{M}$. The effect of the concentrations of $\mathrm{Ce}(\mathrm{IV})$ on the system was investigated by determining the CL intensity of Ru(bipy) $3^{2+}$-Ce(IV) system (blank) and Ru(bipy) ${ }^{2+}$-Ce(IV)-MA. From the experimental results shown in Figure 4, it was seen that when the concentration of Ce(IV) increased from $3.33 \times 10^{-5}$ to $2.3 \times 10^{-3} \mathrm{M}$ the $\mathrm{CL}$ intensity of Ru(bipy) ${ }_{3}{ }^{3-}$-Ce(IV)-MA system increased and after the concentration of $\mathrm{Ce}$ (IV) exceeded $2.3 \times 10^{.3} \mathrm{M}$. the intensity decreased which may be due to the absorption of light emission by the colored Ce(IV) solution and the scattering of light emission by the unsolvable hy'droly sis product of $\mathrm{Ce}$ (IV) at the experimental acidity. ${ }^{1.9}$ For this reason, $2.3 \times 10^{-3} \mathrm{M}$ of $\mathrm{Ce}(\mathrm{IV})$ was selected for further experiments.

Effect of mineral acids. The effects of $\mathrm{H}_{2} \mathrm{SO}_{4} \mathrm{HNO}_{3}$ and $\mathrm{HCl}$ in the $\mathrm{Ce}$ (IV) solution were studied. The relative intensities were 100.0 .85 .2 and $55.0 \%$ respectively. In the presence of $\mathrm{H}_{2} \mathrm{SO}_{4} \mathrm{CL}$ intensity was maximum. Thus $\mathrm{H}_{2} \mathrm{SO}_{4}$ was chosen for subsequent studies. In the solution of $\mathrm{H}_{2} \mathrm{SO}_{4}$. the Ce(IV) species exist as sulfated complexes. such as. $\mathrm{Ce}\left(\mathrm{SO}_{4}\right)^{)^{+}}$. $\mathrm{Ce}(\mathrm{OH})\left(\mathrm{SO}_{4}\right)^{+}, \mathrm{Ce}\left(\mathrm{SO}_{4}\right)_{2}$. $\mathrm{Ce}\left(\mathrm{SO}_{4}\right)_{3}{ }^{2-} . \mathrm{HCe}\left(\mathrm{SO}_{4}\right)_{3}{ }^{-} . \mathrm{HCe}\left(\mathrm{SO}_{4}\right)_{4}{ }^{3-}$ and $\mathrm{Ce}\left(\mathrm{SO}_{4}\right)_{4}{ }^{+-}$. ${ }^{30}$ and these species are in a series of equilibria with $\mathrm{HSO}_{+}^{-}$. It has already been pointed out that the reactive species of the oxidants are $\mathrm{Ce}(\mathrm{IV}) . \mathrm{Ce}\left(\mathrm{SO}_{4}\right)_{2}$ and $\mathrm{HCe}\left(\mathrm{SO}_{4}\right)^{3-1} \cdot 1 .-2 \mathrm{So}$. the concentration of $\mathrm{H}_{2} \mathrm{SO}_{4}$ is a very important parameter for the $\mathrm{CL}$ reaction involving in $\mathrm{Ce}$ (IV). In order to find the optimun concentration of $\mathrm{H}_{2} \mathrm{SO}_{4}$ used for the chemiluminogenic reaction for the determination of MA. the effect of $\mathrm{H}_{2} \mathrm{SO}_{4}$ concentration on the $\mathrm{CL}$ intensity obtained from the Ru(bipy) $3^{-2}-\mathrm{Ce}$ (IV)-MA system was investigated. With the solutions containing a variable anount of

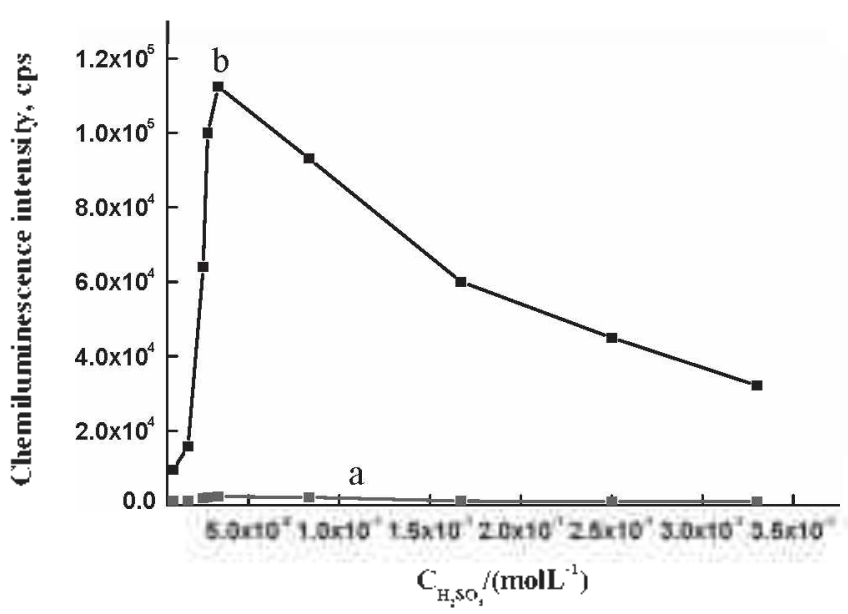

Figure 5. Eftect of the concentration of $\mathrm{H}_{2} \mathrm{SO}_{4}$ on chemiluminescence intensity. Conditions: $3.3 \times 10^{-3} \mathrm{~mol} \mathrm{~L}^{-1}$ mandelic acid. $6.7 \times 10^{-t}$ mol L Ru(bipy) ${ }_{3}{ }^{2-}$ and $2.3 \times 10^{-3} \mathrm{~mol} \mathrm{~L}^{-1}$ Ce(IV); (a) Ru (bipy) ${ }_{3}{ }^{3+}$ Ce(IV) system! (b) Ru(bipy) ${ }_{3}{ }^{2-}$-mandelic acid-Ce(IV) system.

$\mathrm{H}_{2} \mathrm{SO}_{4}$ from $8.3 \times 10^{-2} \mathrm{M}$ to $0.33 \mathrm{M} \mathrm{H}_{2} \mathrm{SO}_{4}, 6.7 \times 10^{-4} \mathrm{M}$ of Ru(bipy) $3_{3}^{3-} .3 .3 \times 10^{-3} \mathrm{MMA}$ and $2.3 \times 10^{-3} \mathrm{MCe}(\mathrm{IV})$. the effect of the concentrations of $\mathrm{H}_{2} \mathrm{SO}_{4}$ on the sy stem was investigated by detenmining the $\mathrm{CL}$ intensity of Ru(bipy) $)_{3}^{-2}-\mathrm{Ce}(\mathrm{IV})-\mathrm{MA}$. From the experimental results shown in Figure 5, the maximum intensity reached at $3.3 \times 10^{2} \mathrm{MH}_{2} \mathrm{SO}_{4}$. When the $\mathrm{H}_{2} \mathrm{SO}_{4}$ concentration was above this level. the light intensity started to decrease which indicates that under this concentration condition, the amounts of the reactive species of the oxidants in the solution is maximum Hence, $3.3 \times 10^{-2} \mathrm{MH}_{2} \mathrm{SO}_{4}$ was used for the deternination of MA.

Effect of flow rate on the chemiluminescence intensity. The flow rate is an important parameter in CL detection as the time taken to transfer the excited product into the flow cell is critical for maxinum collection of the enitted light. ${ }^{21}$ In order to achieve maximum CL intensity, total flow rates between $I$ and $4.5 \mathrm{~mL} \mathrm{~min}^{-1}$ were tested with equal flow rates in each channel of both pumps. CL intensity increased as the flow rate increased and reached maxinum at $2.0 \mathrm{~nL} \mathrm{nun}{ }^{-1}$. Further increasing the flow rate did not change the analytical signal significantly. Low flow rate resulted in an increased residence time ( $>41$ second). It was observed that reagent consuntption increased and peak shape as well as measurement rate were affected simultaneously with higher flow rate. Therefore a flow rate of $2.0 \mathrm{~mL} \mathrm{minn}^{-1}$ in each channel was recommended considering greater precision. and economy in the use of reagents.

Effect of sample volume on the chemiluminescence intensity. When the sample injection volume was varied in the range 50-400 $\mu \mathrm{L}$. the peak height increased and reached maximum at $250 \mu \mathrm{L}$. After that, the height remained almost constant above this value. At very large sample volumes $(>300 \mu \mathrm{L})$, double peaks were observed probably due to the very high dispersion values at the edges and very low values in the centre because of limited dispersion of the carrier into the analyte and distortion in concentration gradient within the flow. A volume of $250 \mu \mathrm{L}$ was recommended for all remaining experiments. 


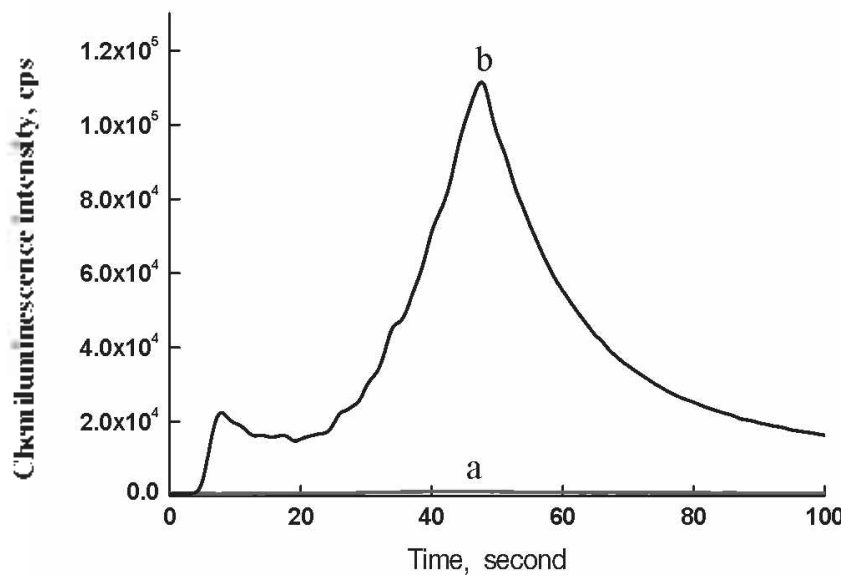

Figure 6. The CL kinetic curves of the systems. Conditions: $3.3 \times 10^{-3}$ mol L ${ }^{-1}$ mandelic acid, $6.7 \times 10^{-4} \mathrm{~mol} \mathrm{~L}^{-1}$ Ru(bipy) ${ }^{2+} 2.3 \times 10^{-3} \mathrm{~mol} \mathrm{~L}^{-1}$ $\mathrm{Ce}$ (IV) and $3.3 \times 10^{-2} \mathrm{~mol} \mathrm{~L}^{-1} \mathrm{H}_{2} \mathrm{SO}_{4}$ ( (a) Ru(bipy) ${ }^{2+} \mathrm{Ce}$ (IV) system; (b) Ru(bipy) ${ }^{2+}$-nandelic acid-Ce(IV) system. *The CL intensity of (a) is amplified 100 times.

CL kinetic curves of the systems. The CL kinetic curves of $\mathrm{Ru}(\text { bipy })_{3}{ }^{-+}-\mathrm{Ce}$ (IV) and Ru(bipy) $)_{3}{ }^{--}-\mathrm{MA}-\mathrm{Ce}$ (IV) systems were constructed with the recorder, which are shown in Figure 6. Ru(bi$\mathrm{py})_{3}{ }^{2-}$-Ce(IV) system has an ultra-weak CL. Adding MA into the system can largely enhance its CL intensity and the value of enhancement is proportional to the concentration of MA added. By this property. MA can be deternined sensitively with $\mathrm{CL}$ method.

Calibration and detection. In order to obtain a calibration curve (Figure 7) for MA. a series of standard solutions ( $\mathrm{N}=11$ ) of MA were added to the Ru(bipy) ${ }^{{ }^{2-}}$-Ce(IV) system under the optimized experimental conditions: $\left[\mathrm{Ru}\right.$ (bipy) $\left.{ }^{{ }^{2-}}\right]=$ $6.7 \times 10^{-4} \mathrm{M} .[\mathrm{Ce}(\mathrm{IV})]=2.3 \times 10^{-3} \mathrm{M} .\left[\mathrm{H}_{2} \mathrm{SO}_{4}\right]=3.3 \times 10^{-2} \mathrm{M}$ and the $\mathrm{CL}$ were recorded. The experimental results show that under the optimum conditions noted above. the responses of CL intensity are linear to the concentrations of MA in the range of $1.46-3+2.0 \mu \mathrm{g} / \mathrm{mL}$. The linear regression equation is $\mathrm{Y}=$ $37887.72 \log X-65701.13(R=0.99732$. where $X$ is the concentration of MA expressed in $\mu \mathrm{g} / \mathrm{mL}$ and $\mathrm{Y}$ is the CL intensity (cps unit). The limit of detection (LOD) as defined by IUPAC. $\mathrm{C}_{\mathrm{L} O \mathrm{D}}=3 * \mathrm{Sb} / \mathrm{m}$ (where $\mathrm{Sb}$ is the standard deviation of the blank signals and $\mathrm{m}$ is the slope of the calibration graph) was found to be $0.072 \mathrm{lg} / \mathrm{mL}$. The relative standard deviation for 10 repeated measurements was $1.80 \%$.

Interferences studies. Considering that the developed method would be applied to determine MA in tablets and urine sample the interference effect of common ions and several compounds commonly used as excipients and generally presented in urine sample was assessed. Samples containing $\mathrm{MA}$ at a fixed concentration of $3.6 \times 10^{-4} \mathrm{~mol} / \mathrm{L}$ and increasing concentration of the interferences were analyzed by the method. The tolerable limit of a foreign species was taken if it caused a relative error of less than $5 \%$. Under the optimized conditions. the common ions and the studied excipients at concentrations usually found in the tablets did not interference the determination of MA. So the content of MA in tablet could be determined after filtration without any pretreatment.

Analytical applications. The proposed method was used to analyze urine samples from 5 volunteers. The samples were

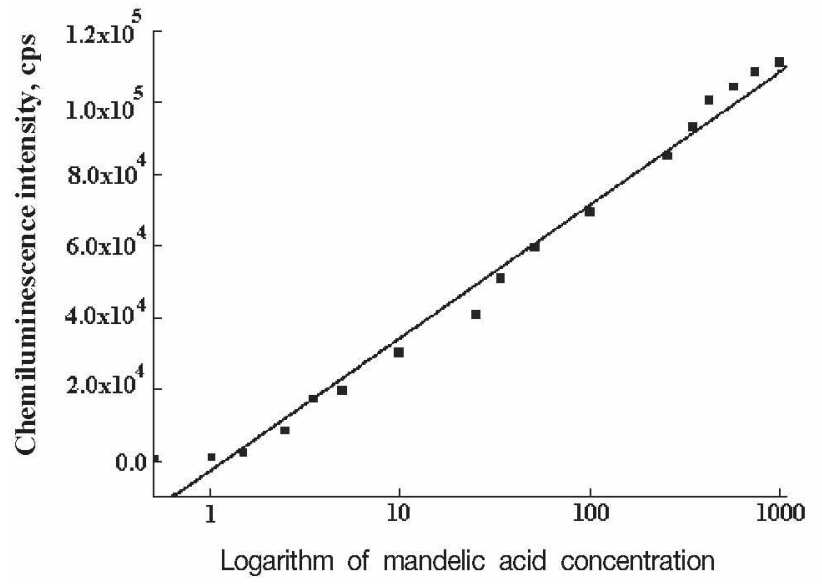

Figure 7. Calibration curve for mandelic acid. Conditions: $6.7 \times 10^{+}$ mol L ${ }^{-1}$ Ru(bipy)s ${ }^{2+}, 2.3 \times 10^{-3} \mathrm{~mol} \mathrm{~L}^{-1} \mathrm{Ce}(\mathrm{IV})$ and $3.3 \times 10^{-2} \mathrm{~mol} \mathrm{~L}^{-1}$ $\mathrm{H}_{2} \mathrm{SO}_{4}$.

found to contain no MA. so they were spiked with MA at variable concentrations. Table 1 shows the results obtained in the deternination of MA. As can be seen, the differences between the concentrations added and those found were small in all cases. Therefore, the proposed method can be reliably applied to real samples. Recoveries ranged from 94.6 to $105.0 \%$. The proposed method was applied to the determination of MA in pharmaceutical preparations. The results obtained and the labeled contents are given in Table 2. There were no significant differences between labeled contents and those obtained by the proposed method. Recovery studies were also performed on each of the analyzed samples by reconmended treatment. Recoveries ranged from 97.5 to $102.5 \%$.

Possible mechanism of the present CL system. In all reported cases involving $\mathrm{Ru}(\text { bipy })_{\mathrm{s}}{ }^{2+}$. CL reactions occur upon the following sequence of reactions:

$$
\begin{aligned}
& \operatorname{Ru}(\text { bipy })_{3}{ }^{2+} \longrightarrow \operatorname{Ru}(\text { bipy })_{3}{ }^{3-} \text { (oxidation) } \\
& \operatorname{Ru}(\text { bipy })_{3}{ }^{3+} \longrightarrow \operatorname{Ru}(\text { bipy })_{3}{ }^{2-*} \text { (reduction with the analyte) } \\
& \operatorname{Ru}(\text { bipy })_{3}{ }^{2+} \longrightarrow \operatorname{Ru}(\text { bipy })_{3}{ }^{2-}+h:(C L \text { emission })
\end{aligned}
$$

Common to all analytical applications the fonmation of the reagent. Ru(bipy $)_{3}{ }^{\text {s+ }}$. is either by chemical photochemical or electrochemical oxidation of Ru(bipy) $)_{3}{ }^{2-}$. 2 Ru(bipy) ${ }_{3}{ }^{2-}$ is not a sufficiently strong reductant to reduce organic acids like

Table 1. Determination of MA in urine sample

\begin{tabular}{cccc}
\hline & \multicolumn{3}{c}{ Mandelic acid } \\
\cline { 2 - 4 } Urine sample & $\begin{array}{c}\text { Added } \\
\left(\mu g \mathrm{~mL}^{-1}\right)\end{array}$ & $\begin{array}{c}\text { Found } \\
\left.(\mu \mathrm{g} \mathrm{mL})^{-1}\right)^{\sigma}\end{array}$ & $\begin{array}{c}\text { Recovery } \\
(\%)\end{array}$ \\
\hline Sample l & 100 & $10.5 \pm 3.3$ & 105.0 \\
Sample 2 & 15.0 & $14.2 \pm 2.9$ & 94.6 \\
Sample 3 & 20.0 & $19.7 \pm 2.1$ & 98.5 \\
Sample 4 & 250 & $24.4 \pm 2.1$ & 97.6 \\
Sample 5 & 30.0 & $29.3 \pm 1.9$ & 97.6 \\
\hline
\end{tabular}

${ }^{a}$ Average of five determinations per sample 
Table 2. Results for the determination of MA in tablets

\begin{tabular}{|c|c|c|c|c|c|}
\hline \multirow{2}{*}{ Sample (tablet) } & \multicolumn{2}{|c|}{ Amount (mg) } & \multirow{2}{*}{$\begin{array}{c}\text { Added } \\
\left(\mu g L^{-l}\right)\end{array}$} & \multirow{2}{*}{$\begin{array}{l}\text { Found } \\
\left(\mu \mathrm{g} \mathrm{mL}^{-1}\right)^{a}\end{array}$} & \multirow{2}{*}{$\begin{array}{c}\text { Recovery } \\
(\%)\end{array}$} \\
\hline & Labled (mg) & Found \pm S.D $(\%)$ & & & \\
\hline \multirow{5}{*}{$\mathrm{MA}$} & \multirow{5}{*}{500} & \multirow{5}{*}{$497.3 \pm 0.93$} & 1.00 & 0.97 & 97.5 \\
\hline & & & 2.00 & 2.05 & 102.5 \\
\hline & & & 300 & 3.02 & 100.6 \\
\hline & & & 4.00 & 3.96 & 99.0 \\
\hline & & & 5.00 & 5.01 & 100.2 \\
\hline
\end{tabular}

${ }^{a}$ Average of tive determinations per sample

pyruvate or citrate in solution, and so the CL reaction does not proceed. $^{3+-? ?}$ Cerium (IV) has a higher reduction potential than Ru(bipy) ${ }_{3}{ }^{-}$and CL emission is observed in the presence of $\mathrm{Ce}$ (IV) because the oxidation of acids forms intermediate radicals of sufficient energy to react with the Ru(bipy) ${ }_{3}{ }^{3-}$ generated from $\mathrm{Ru}$ (bipy) ${ }_{3}^{\text {i- }}$ by oxidation with cerium(IV). In preliminary study. it was also observed that at low concentrations of Ru(bipy $)_{3}{ }^{2+}$ there is little or no CL emission. despite the presence of the optimized $\mathrm{Ce}$ (IV) concentration. By analogy the scheme proposed for MA is:

$$
\begin{aligned}
& \mathrm{Ru}(\text { bipy })_{3}{ }^{2+}-\mathrm{Ce}^{+-} \longrightarrow \mathrm{Ru}(\text { bipy })_{3}{ }^{3-}+\mathrm{Ce}^{3+} \\
& \mathrm{C}_{6} \mathrm{H}_{5} \mathrm{CH}(\mathrm{OH}) \mathrm{COO}^{-}+\mathrm{Ce}^{1+} \longrightarrow \mathrm{C}_{6} \mathrm{H}_{5} \mathrm{CH}(\mathrm{OH}) \mathrm{COO}+\mathrm{Ce}^{3-}(2) \\
& \mathrm{C}_{6} \mathrm{H}_{5} \mathrm{CH}(\mathrm{OH}) \mathrm{COO}-\mathrm{C}_{6} \mathrm{H}_{5}{ }_{5} \mathrm{C} H(O H)+\mathrm{CO}_{2} \\
& \text { Ru(bipy) }{ }_{3}^{3+}-\mathrm{C}_{6} \mathrm{H}_{5} \dot{\mathrm{C}} \mathrm{H}(\mathrm{OH}) \rightarrow \mathrm{C}_{6} \mathrm{H}_{5} \mathrm{CHO}-\mathrm{Ru}(\text { bipy })_{3}{ }^{2--}+\mathrm{H}^{-} \\
& \text {Ru(bipy } \left.)_{3}{ }^{2+*} \longrightarrow \text { Ru(bipy) }\right)^{2+}-h v(610 \mathrm{~nm})
\end{aligned}
$$

The mechanism involves the oxidation of Ru(bipy) ${ }_{3}{ }^{-}$and MA by Ce(IV). The oxidation product of acid undergoes decomposition to form a radical. This reduces the $\mathrm{Ru}(\mathrm{bipy}){ }_{3}{ }^{3-}$ to the excited state that subsequently emits light $(610 \mathrm{~nm})$ with the formation of benzaldehy'de as by-product.

\section{Conclusion}

The proposed chemiluminescence detection method has proved to be simple. rapid and sensitive for MA determination. This preliminary study shows that mandelic acid exhibits analytically useful chemiluminescence upon reaction with tris (2.2'-bipyridyl) ruthenium(II) and acidic Ce(IV). The linear range and detection limit are $1.46-342.0 \mathrm{\mu g} / \mathrm{mL}$ and $0.072 \mathrm{\mu g} /$ $\mathrm{mL}$. respectively. The chemiluminescence method proposed here is relatively simple and showed significant selectivity. The results indicated that the proposed chemiluminescence reaction system is not only appropriate for flow injection analysis but is also convenient for batch type systems due to intense chemiluminescence signal. Utilizing the proposed method. the MA content of commercial tablets as well as in urine sample can be determined with reasonable selectivity.
Aclnowledgments. This work was supported by Korea Research Foundation Grant (KRF-2006-005-J02402).

\section{References}

1. Mohammed, Z; Lourdes, A.; Angel, R.; Miguel, V. J. Chrontat. A 2006, 1104, 331.

2. Vodicka, P.; Koskinen, M.; Naccarati, A.; Oesch-Bartlomowicz, B.; Vodickova, L.; Hemminki, K.; Oesch, F. Dnig. Hetab. Rev 2006, 38.805

3. Zhang, X. X, Chakrabarti, S.; Malick, A. M.; Lricher, C. Mntot. Res. 1993,302,213.

4. Linhart, I.; Smejkal, J.; Mádková, I. Toxicol. Lett. 1998, 9f, 127.

5. Yamamoto, K.; Fujimatsu, I; Komatsu, K. J. Fement. Bioeng. $1992,73,425$.

6. Kaul, P; Banerjee, A; Mayilraj, S:- Banerjee, U. C. Tetwathon Asmmeth 2004, 15, 207.

7. Wang, T. Z; Wang, X. T.; Tang, Y. H.; Shen, S. J.; Jin, Y. X.; Zeng, S. J. Chronat. B, Analy. Technol Bioned Life Sci. 2006, 8t0, 50 .

8. Zougagh, M.: Arce, L.; Rios, A.: Valcarcel, M. J. Chromat. At 2006, 1104,331.

9. Kezic, S.; Jakasa, I: Wenker, M. J. Chromat. B: Bioned. Sci. Appl. 2000, 738, 39

10. Huang, Y.; Xiao, M.; Shi, X.; Meng, C.; Guo, Y. Yaow Fenti Zazhi 2004, 2٪,460.

11. Wu, C.; Kong, D.; Qiu, B. Fulian Fenxi Ceshi 2004, 13, 1937.

12. Nicholson, J. D. Anatyst $1969,94,413$

13. Tounshend, A. Anatust 1990, 115, 495.

14. Robards, K; Worsfold, J. Anat. Chm .4cta 1992, 266, 147.

15. Hindson, B. J.: Bamett, N. W. Anal Chim .Acta 2001, $475,1$.

16. Gerardi, R. D.; Banett, N. W.; Lewis, S. W. Anal. Chim. Acta $1999,378,1$

17. He, Z. K.: Gao, H.: Yuan, L. J.: Luo, Q. Y.: Zeng, Y. E. Anahst 1997, 122, 122

18. Barnett, N. W.; Hindson, B. J.: Lewis, S. W.; Purcell, S. D. Anal. Contmun. 1998, 35, 321

19. Xi, T: Shi, B.: Ai, X: He, Z. J. Pham Biomed Anal 2004, 36, 237.

20. Muhammal, B. S. S.: Vijayachander, R. K. Bull. Chem. Soc. Jpn. $1963,36,949$.

21. Lakshmi, S.; Renganathan, R. Int. J. Chem. Kinet. 1996, $28,713$.

22. Meng, H.; Wu, F.; He, Z; Zeng, Y. Talanta 1999, +8, 571 .

23. Geradi, R. D.: Barnett, N. W.; Lewis, S. W. Anal Chim .Acta 1999. 378,1

24. Rubinstein, I.; Bard, A. J. J. Am. Chem. Soc 1981, 103, 515

25. Knight, A. W.: Greenway, G. M. Analust 1995, 120, 2543.

26. He, Z; Gao, H.; Yuan, L.; Zeng. Y. Analyst 1997, 122, 1343.

27. Perez-Ruiz, T.; Martinez-Lozano, C.; Tomas, V;; Fenoll, I. Anal Chim . Acta 2003, $\$ 85,63$. 